
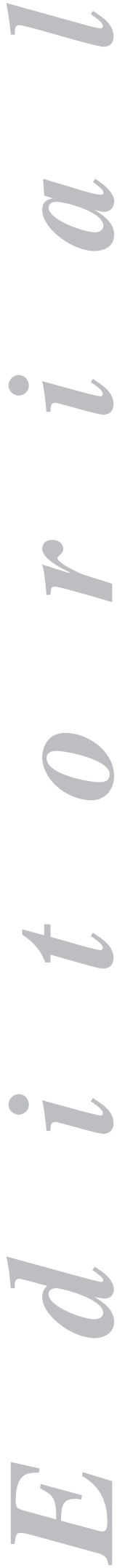

\section{Role of Helicobacter pylori in gastric cancer following partial gastrectomy for benign ulcer}

\section{Introduction}

During the 1970s, Correa (1) formulated his theory on the sequence of histological changes from type B chronic gastritis to gastric cancer, through intermediate atrophic gastritis, intestinal metaplasia, and dysplasia stages. Based on epidemiological studies, it was suggested that the initial stage in this process, that is, initial gastritis, could result from environmental factors such as diets rich in salt and nitrates, and poor in vegetables and fresh fruits. In 1983, Marshall and Warren (2) demonstrated that mucosal inflammation was caused by the organism Helicobacter pylori $(\mathrm{Hp})$, and thus they first related gastric cancer to $\mathrm{Hp}$, a view that was supported by case-control studies and meta-analyses (3-5) showing a 2 to 4 -fold increase in the risk for gastric cancer among the infected population when compared to the noninfected population. In 1994, IARC (International Agency for Research on Cancer dependent of the World Health Organization) defined $H p$ as a type I carcinogen (6), matching it, for instance, with the association between smoking and lung cancer.

All studies suggest that cancer development requires the presence of $H p$ for many years; in other words, it is required that infection be initiated at an early age. Furthermore, some studies suggest that the association between $\mathrm{Hp}$ and cancer is more obvious in early versus advanced cancer (7). Similarly, this correlation is more apparent if infection was diagnosed years before the diagnosis of cancer $(4,8)$, which suggests that their relationship may be underestimated because of potential infection clearance during disease development. A recent German study (9) compared 68 patients with gastric cancer (excluding cardia cases) versus 360 control individuals; a serology performed a few years before had shown that $78 \%$ of patients with cancer were infected versus $63 \%$ among controls, which represented an odds ratio (OR) of 3.7 that may reach 5.7 in patients with $H p$ CagA + infection.

A Spanish study (10) demonstrated that the prevalence of infection was not different for intestinal-type and diffuse-type gastric carcinoma (incidence, 69\%), but significant differences were found in the prevalence of $H p$ for distal cancer, which was of $73.6 \%$ versus only $48.6 \%$ for cardial cancer, the latter with no differences versus the prevalence of infection in the control population.

While infection is present in more than $80 \%$ of patients with gastric cancer, most infected persons will not develop the latter condition, which suggests that $H p$ is a nearly necessary but insufficient factor. In fact, the prevalence of gastric cancer does not always correlate with the prevalence of infection; for example, areas with a high (Japan) or low (sub-saharian Africa) incidence of gastric cancer have a similar prevalence of infection. Even in regions with a high incidence of $H p$ and cancer, the latter will only develop in $2 \%$ of infected individuals. It is widely accepted that less 
than $1 \%$ of all infected subjects will eventually develop gastric cancer. Thus, research efforts should focus on the identification of factors leading to gastric cancer in a few, but not most $\mathrm{Hp}$-infected patients.

\section{What factors may influence the potential development of gastric cancer?}

1. Bacterial factors. Experimental and epidemiological studies (9) demonstrate a higher association of CagA + germs with gastric cancer. In cell cultures (11), $\mathrm{Hp}$ CagA + showed its ability for cell invasion, activating MMP-9 (Matrix MetalloProteinase-9), VEGF (Vascular Endothelial Growth Factor) and COX-2 (Cyclooxigenase), and the disruption of apical junctions in superficial gastric cells (12); both characteristics lead to a higher direct or indirect ability for inflammation induction. A meta-analysis (13) identified 16 qualified studies comprising 2,284 patients with gastric cancer and 2,770 control subjects. Both $\mathrm{Hp}$ and CagA, increase the risk for gastric cancer by 2.28 and 2.87 , respectively. Cardial cancer is associated with none of these two parameters. In a Swedish study (14) differences were more apparent $-81 / 100$ (81\%) patients with gastric cancer are infected: $86 \%$ with CagA + germs versus $58 \%$ and $54 \%$, respectively, for controls (OR 7.4 among $\mathrm{Hp} \mathrm{CagA}+$ patients $v s$. non-infected subjects).

2. Environmental factors. Helicobacter pylori may induce gastric cancer in experimental animals, while the presence of a prior carcinogen is a requirement in most studies $(15,16)$. Studies searching for the cellular origin of cancer in $\mathrm{Hp}$-infected rats led to the surprising finding that gastric cancer may originate in the socalled BMDC (Bone Marrow-Derived Stemp Cells) (17). Similarly, achlorhydria has been shown to produce hypergastrinemia and bacterial overgrowth in the rat, which in turn increases inflammation and atrophic gastritis. However, no evidence worldwide has ever proven that the inhibition of secretion using PPIs (proton pump inhibitors), which elevates blood gastrin and induces no bacterial overgrowth, will increase the incidence of gastric cancer (18). We already discussed that a diet rich in vegetables and fresh fruits containing ascorbic acid and tocopherol has protective effects, while a diet rich in animal proteins and nitrites favors the development of cancer, as does smoking $(\mathrm{OR}=2.3)$, but only in infected subjects (19).

3. Immune-hereditary factors. Hp-infected first-grade relatives of patients with gastric cancer have a higher proportion of atrophic gastritis and other precancerous factors when compared to infected control subjects with no family history of gastric cancer (20), and have increased interleukin-1- $\beta$ (Il-1- $\beta$ ) and TNF- $\alpha$, and decreased Il-10 levels, which rises the risk for gastric cancer in infected versus non-infected subjects 27 fold (21). Such evidence has led to recommend eradication in $\mathrm{Hp}$-infected first-grade relatives of patients with gastric cancer.

\section{Is eradication indicated for prevention of gastric cancer?}

There is no definite evidence to answer this question, and such evidence will likely be difficult to obtain, since thousands of citizens randomized to eradication or placebo with many years of follow-up would be required. However, indirect evidence available may help reasonably answer this question, however with insufficient strength. 
A Japanese study (22) in $132 \mathrm{Hp}+$ patients undergoing endoscopical resection for early gastric cancer is interesting. Infection was eradicated in 65 patients who had no tumor relapse at 5 years, whereas 9/67 (13\%) patients who received no eradication relapsed. This finding is suggestive but has limitations, since the study design was not double-blind. Another Japanese study (23) followed for a mean 3.5 years 1,120 patients with ulcer disease; 8/944 (0.8\%) patients with successful eradication developed gastric cancer versus a higher percentage -4/176 (2,2\%)- who had persistent infection; differences did not reach significance. It could be acknowledged that all patients who developed cancer had suffered from gastric ulcer. No patient with duodenal ulcer developed gastric cancer.

Despite the difficulties suggested regarding an interventional study in both healthy and infected subjects to demonstrate preventive efficacy for gastric cancer using eradication in both healthy and symptomatic individuals, one such study (24) has been reported in China, in a high-risk region for gastric cancer and in "only" 1,630 individuals who were followed for 7.5 years. Eighteen cases of gastric cancer were identified during the study period, with no significant differences between those who received eradication $(n=7)$ and those who received placebo $(n=11)(p=$ 0.3 ). Despite this scarcely encouraging result, none of the eradicated patients lacking histological mucosal lesions considered precancerous at baseline eventually developed cancer, versus 6 patients in the placebo group $(p=0.02)$, which suggests that in the absence of such histological lesions eradication seems to prevent cancer development, while a point of no return seems to exist when therapy occurs once these changes have already developed.

In the recent Spanish consensus conference on the indications of eradication (25) it was recommended that "given the high prevalence of $H p$ worldwide, eradication cannot be performed to prevent gastric cancer, and its yield in terms of cost-effectiveness is unwise"; it may only be accepted, as previously suggested, for first-grade relatives of patients with gastric cancer.

\section{Is eradication indicated in the gastric remnant following partial gastrectomy for gastric cancer?}

From evidence discussed in previous sections, the benefits of $\mathrm{Hp}$ eradication in the remaining gastric stump following gastrectomy for gastric cancer are easily deductible. Furthermore, clinical studies demonstrate that following gastrectomy for cancer there are greater neutrophil infiltrates and increased COX-2 in the $\mathrm{Hp}$-infected mucosa versus the non-infected gastric mucosa in the gastric remnant, and these findings suggest a higher potential for malignant relapse in the presence of $H p$ (26).

A recent study (27) in a group of patients with gastrectomy for early gastric cancer and presence of $\mathrm{Hp}$ at the stump, eradication dramatically reduced mononuclear cell infiltrates, virtually erased neutrophil infiltrates, and significantly diminished IL-8 and Ki-67 tissue levels. The authors concluded that, prior to eradication, the gastric remnant mucosa of patients operated on for gastric cancer (even early gastric cancer) exhibits histological changes considered to confer a high risk of carcinogenesis as a result of inflammation, a risk that at least theoretically may be minimized with $H p$ eradication.

Therefore, the recommendation by the Spanish consensus conference (25) seems appropriate, as it indicates eradication in patients operated on for gastric cancer by means of partial gastrectomy where the presence of infection is demonstrated; even 
if this recommendation has only an evidence level of 4 (evidence 4 is based on case report series, cohort studies, and case-control studies).

\section{Is eradication indicated in the gastric remnant following partial gastrectomy for benign gastric ulcer disease?}

Patients undergoing partial gastrectomy for benign peptic ulcer disease (mainly gastric ulcer) are considered to have an increased risk of cancer development in the gastric remnant, and risk was suggested to be higher at 15 years after surgery. Some authors even recommended endoscopy and multiple biopsies in this subgroup as of 10-15 years after surgery for potential early diagnosis purposes. Bile reflux and the presence of $H p$ were even suggested as pathogenic causes (28).

The following questions may be posed:

1. Does Helicobacter pylori remain for years in the gastric remnant following gastrectomy for ulcer? A German study adequately answers this question (29). Endoscopy, biopsy, and Helicobacter pylori tests were performed for 57 patients at a mean of 20 years after gastrectomy for peptic ulcer. In 25/57 (43.8\%) patients the germ was detected in biopsy specimens. Gastric atrophy was more common in infected subjects, but not gastritis severity. Therefore, fewer than half of patients gastrectomized for ulcer have $\mathrm{Hp}$ in the gastric remnant.

2. How is Helicobacter pylori associated with ulcer relapse? It is a well known fact that ulcer relapse after eradication in non-operated patients occurs almost exclusively in $\mathrm{Hp}+$ individuals either from reinfection or recrudescence. However, in a recent study (30) in 186 patients gastrectomized for benign ulcer, 83 (44.6\%) had ulcer relapse and of these only $36 \%$ were $H p+$, with no significant differences versus those with no ulcer relapse. The authors conclude that in the case of gastrectomy $\mathrm{Hp}$ infection plays a role not as relevant in relapse as is the case with patients not undergoing surgery; as a result, eradication to prevent ulcer relapse is scarcely supported.

3. Is there a greater risk for cancer development in the gastric stump, versus the control population, in patients gastrectomized for peptic ulcer, and is that potentially related to Helicobacter pylori? The role of $\mathrm{Hp}$ in the development of gastric cancer in the gastrectomy stump for benign ulcer is controversial and has been considered even unlikely, since, as previously discussed, the germ is only present in approximately $40 \%$ of patients, perhaps as a consequence of bile reflux conditioning an alkaline environment in the remnant unfavorable for this organism. Alkaline reflux has been even postulated as the most relevant factor involved in the pathogenesis of stump cancer (31).

In this issue of Revista Española de Enfermedades Digestivas, Seoane et al. contribute a review of 73 patients undergoing partial gastrectomy for benign ulcer who were examined using endoscopy, biopsies, and adequate histology. First of all, the high percentage of gastrectomized patients with infection (86\%), far above that usually described in the literature (40\%) is striking; furthermore, $15(20.5 \%)$ patients were diagnosed with cancer in the gastric remnant, with all of them being $\mathrm{Hp}+$ and with a mean time from gastrectomy to diagnosis of 32 (14-48) years. This percentage of cancer development in the gastric remnant is also one of the highest ever described in the literature.

The authors reached the following conclusions:

-Cancer development in the gastric stump following gastrectomy for benign ulcer is not negligible (20\%). 
- Cancer development in the stump occurs after 15 years following surgery.

- The pathogenesis of cancer is more related to the presence of $\mathrm{Hp}$ than to bile reflux in view of the high percentage of infected patients (86\%) in their experience.

-As a logical consequence of their findings, an indication for eradication is intuited in these patients, much in the same way as in patients gastrectomized for gastric cancer.

The information provided by the authors is relevant and useful. However, we would like to contribute some remarks.

- The $20 \%$ rate for gastric stump cancer as diagnosed by endoscopy refers to gastrectomized patients who presented because of discomfort or at best because of referral by a practitioner for early cancer diagnosis, but who surely are not representative of the whole group. As a result, the overall percentage of cancer development is surely smaller.

- The information that all patients were diagnosed with cancer after 32 years on average is important; even more relevant is the fact that the diagnosis was reached between 14 and 48 years of age, which confirms that cancer development occurs as was traditionally suggested, namely at least at 15 years after resective surgery.

- In our setting, the mean percentage of $\mathrm{Hp}$ infection in the adult control population is around $50 \%$ (32), and reaches $60-70 \%$ in patients older than 60 years. Therefore, the percentage of infection found by the authors in their patients is not surprisingly high, particularly considering that these are ulcer patients. However, this possible explanation must be qualified, as also gastrectomized patients reported in the literature are ulcer patients with a higher prevalence of infection.

-While the authors do not clearly specify whether they consider eradication as indicated, they seemingly tend towards this possibility in view of their final conclusion -"Infection by Helicobacter pylori may play a role in gastric cancer"-, obviously referring to gastric cancer as developing after gastrectomy for peptic ulcer. However, this indication is not included in the Spanish consensus conference (25) or other previous meetings, and further studies are needed to confirm the relevant findings in this review. Anyway, and according to a recently published study (33), eradication in gastrectomized patients results in a higher efficacy rate when drugs are taken in a lying position and with the body turned to the left for some 30 minutes.

J. Monés

Service of Gastroenterology. Hospital de la Santa Creu i Sant Pau. Barcelona, Spain

\section{REFERENCES}

1. Correa P. Human gastric carcinogenesis: a multistep and multifactorial process - first American Cancer Society Award Lecture on Cancer Epidemiology and Prevention. Cancer Res 1992; 15 (52): 1132-6.

2. Marshall BJ, Warren JR. Unidentified curved bacilli in the stomach of patients with gastritis and gastric ulceration. Lanced 1984; 1: 1311-5.

3. Parsonnet J, Friedman GD, Vandersteen P, Chang Y. Helicobacter pylori infection and the risk of gastric carcinoma. N Engl J Med 1991; 325: 1127-31.

4. Ekstrom AM, Held M, Hansson LE, Engstrand L, Nyren O. Helicobacter pylori in gastric cancer established by CagA immunoblot as a marker of past infection. Gastroenterology 2001; 121: 784-91.

5. Fox JG, Wang TC. Helicobacter pylori -not a good bug after all! N Engl J Med 2001; 345: 829-32.

6. IARC Monographs on the evaluation of carcinogenic risk to humans, vol 61. Lyon: Wold Health Organization, 1994: 177-240. 
7. Huang JQ, Sridhar S, Chen Y, Hung RH. Meta-analysis of the relationship between Helicobacter pylori seropositivity and gastric cancer. Gastroenterology 1998; 114: 1169-79.

8. Helicobacter and Cancer Collaborative Group. Gastric cancer and Helicobacter pylori: a combined analysis of 12 case control studies nested within prospective cohorts. GUT 2001; 49: 347-53.

9. Brenner H, Arndt V, Stegmaier C, Ziegler H, Rothenbacher D. Is Helicobacter pylori infection a necessary condition for noncardia gastric cancer? Am J Of Epidemiol 2004: 159: 252-8.

10. Seoane A, Bessa X, Balleste B, O'Callaghan E, Panades A, Alameda F, et al. Helicobacter pylori y cáncer gástrico. Relación con subtipos histológicos y localización del tumor. Gastroenterol Hepatol 2005; 28: 60-4.

11. Wu CY, Wang C J, Tseng CC, Chen HP, Wu MS, Lin JT, et al. Helicobacter pylori promote gastric cancer cells invasion through a NF-кB and COX-2 mediated pathway. World J Gastroenterol 2005; 11 (21): $3197-$ 203.

12. Amieva MR, Vogelmann R, Covacci A, Tompkins LS, Nelson WJ, Falkow S. Disruption of the epithelial apical junctional complex by Helicobacter pylori CagA. Science 2003; 300: 1430-4.

13. Huang JQ, Zheng GF, Sumanac K, Irvine J, Hunt RH. Meta-analysis of the relationship between CagA seropositivity and gastric cancer. Gastroenterology 2003; 125: 1636-44.

14. Heald M, Engstrand L, Hansson LE, Bergstrom T, Nyren O. Is the association between Helicobacter pylori and gastric cancer confined to CagA-positive strains? Helicobacter 2004; 9: 271-7.

15. Watanabe T, Tada M, Nagai H, Sasaki S, Nakao M. Helicobacter pylori infection induces gastric cancer in Mongolian gerbils. Gastroenterology 1998; 115: 642-8.

16. Tatematsu M, Tsukamoto T, Mizoshita T. Role of Helicobacter pylori in gastric carcinogenesis: the origin of gastric cancers and heterotopic proliferative glands in Mongolian gerbils. Helicobacter 2005; 10(2): 97-106.

17. Houghton J, Stoicov C, Nomura S, Rogers AB, Carlson J, Li H, et al. Gastric cancer originating from bone marrow derived cells. Science 2004; 306: 1568-71.

18. Houghton JH, Wang TC. Helicobacter pylori and gastric cancer. A new paradigm for inflammation associated epithelial cancers. Gastroenterology 2005; 128: 1567-78.

19. Siman JH, Forsgren A, Berglund G, Floren CH. Tobacco smoking increases the risk of gastric adenocarcinoma among Helicobacter pylori infected individuals. Scand J Gastroenterol 2001; 36: 208-13.

20. El-Omar EM, Oien K, Murray LS, El-Nujumi A, Wirz A, Gillen D, et al. Increased prevalence of precancerous changes in relatives of gastric cancer patients: critical role of H pylori. Gastroenterology 2000; 118: 2230 .

21. El-Omar EM, Rabkin CS, Gammon MD, Vaughan TL, Risch HA, Schoenberg JB, et al. Increased risk of noncardia gastric cancer associated with proinflammatory cytokine gene polymorphisms. Gastroenterology 2003; 124: 1193-201.

22. Uemura N, Okamoto S. Effect of Helicobacter pylori eradication on subsequent development of cancer after endoscopic resection of early gastric cancer in Japan. Gastroenterol Clin North Am 2000; 29: 819-27.

23. Take S, Mizuno M, Ishiki K, Nagahara Y, Yoshida T, Yokota K, et al. The effect of erradicating Helicobacter pylori on the development of gastric cancer in patients with peptic ulcer disease. Am J Gastroenterol 2005; 100: 1037-42.

24. Wong BC, Lam SK, Wong WM, Chen JS, Zheng TT, Feng RE, China gastric cancer study group. Helicobacter pylori eradication to prevent gastric cancer in high-rick region of China. A randomized controlled trial. JAMA 2004; 291: 244-5.

25. Monés J, Gisbert JP, Borda F, Domínguez-Muñoz E, y grupo conferencia española de consenso sobre Helicobacter pylori. Indicaciones, métodos diagnósticos y tratamiento erradicador de Helicobacter pylori. Rev Esp Enferm Dig 2005; 97: 348-74.

26. Fukuhara K, Osugi H, Takada N, Takemura M, Lee S, Morimura K, et al. Effect of H pylori on COX-2 expression in gastric remnant after distal gastrectomy. Hepatogastroenterology 2004; 51: 1515-8.

27. Hamaguchi K, Ogawa K, Katsube T, Konno S, Aiba M. Does eradication of Helicobacter pylori reduce the risk of carcinogenesis in the residual stomach after gastrectomy for early gastric cancer? Comparison of mucosal lesions in the residual stomach before and after Helicobacter pylori eradication. Langenbechs Arch Surg 2004; 389 (2): 83-91.

28. Lundegardh G, Adami HO, Helmick C, Zack M, Meirick O. Stomach cancer after partial gastrectomy for benign ulcer disease. N Engl J Med 1988; 319: 195-200.

29. Kirsch CH, Madisch A, Piehler P, Bayerdörffer E, Stolte M, Miehlke S. Helicobacter pylori in gastric corpus of patients 20 years after partial gastric resection. World J Gastroenterol 2004; 10: 2557-9.

30. Huang WH, Wang HH, Wu WW, Lai HC, Hsu CH, Chen KS. Helicobacter pylori infection in patients with ulcer recurrence after partial gastrectomy. Hepatogastroenterology 2004; 51: 1551-3.

31. Leivonen M, Nordling S, Haglund C. The course of Helicobacter pylori infection after partial gastrectomy for peptic ulcer disease. Hepatogastroenterology 1998; 45: 587-91.

32. Monés J, Martín de Argila C, Sainz R, Gisbert JP, Sainz S, Boixeda D. Prevalence of Helicobacter pylori in medical professionals in Spain. Eur J Gastroenterol Hepatol 1999; 11: 239-42.

33. Kubota K, Shimizu N, Nosaki K, TakeShita Y, Ueda T, Imamura K, et al. Efficacy of triple therapy plus cetraxate for the Helicobacter pylori eradication in partial gastrectomy patients. Dig Dis Sci 2005; 50: 842-6. 